\title{
The Effect of Short Messaging System- Based Feedback on Physicians' Head CT Scan Ordering Behavior in Neurology and Neurosurgery Departments
}

\author{
Zahra MEIDANI ${ }^{\mathrm{a}, \mathrm{b}}$, Afsaneh MOOSAVI ${ }^{\mathrm{a}}$, Hossein AKBARI ${ }^{\mathrm{c}}$, Felix HOLL He, $^{\mathrm{d}, \mathrm{f}}$ \\ Sahar ZARE ${ }^{\mathrm{a}}$, Ehasn NABOVATI ${ }^{\mathrm{a}, \mathrm{b}, 1}$, Reza DANESHVAR ${ }^{\mathrm{g}}$, Ali MASOUD ${ }^{\mathrm{g}}$, \\ Esmaeel FAKHARIAN $^{\mathrm{h}}$ and Fakhrosadat MIRHOSSEINI ${ }^{\mathrm{i}}$ \\ ${ }^{a}$ Health Information Management Research Center, Kashan University of Medical \\ Sciences, Kashan, Iran \\ ${ }^{\mathrm{b}}$ Department of Health Information Management \&Technology, Kashan University of \\ Medical Sciences, Kashan, Iran \\ ${ }^{\mathrm{c}}$ Department of Biostatistics and Epidemiology, Kashan University of Medical \\ Sciences, Kashan, Iran \\ ${ }^{\mathrm{d}}$ IBE, Ludwig Maximilian University of Munich, Munich, Germany \\ e DigiHealth Institute, Neu-Ulm University of Applied Sciences, Neu-Ulm, Germany \\ ${ }^{\mathrm{f}}$ IGHS, University of California, San Francisco, San Francisco, CA, USA \\ ${ }^{\mathrm{g}}$ Department of Neurology, Kashan University of Medical Sciences, Kashan, Iran \\ ${ }^{\mathrm{h}}$ Trauma Research Center, Kashan University of Medical Sciences, Kashan, Iran \\ ${ }^{\mathrm{i}}$ Department of Anesthesia, Kashan University of Medical Sciences, Kashan, Iran
}

\begin{abstract}
Short messaging system (SMS) works as one of the most popular strategies for physicians' behavior change via sending feedback and reminder messages. One of the areas in which SMS feedback can be effective on physicians' behavior is CT scan ordering. This study investigates the effect of mobile phone SMS feedback on residents' head CT scan ordering at a general teaching hospital in Iran. Through a three-month before-after experimental study, an intervention was conducted, and the CT scans ordered by an individual resident were evaluated every two weeks. Consequently, personal SMS-based feedback was provided to the residents, and the rate of CT per patient in the two phases of the study was analyzed. The mean CT scan ordered per patient decreased from $1.98 \pm 1.09$ to $1.74 \pm 1.45$, and this decrease was insignificant $(\mathrm{P}=0.106)$. SMS-based feedback can reduce head CT scan ordering among residents; whereas this decline was not significant further studies are required to investigate its effectiveness.
\end{abstract}

Keywords. Cell phone, feedback, tomography, X-Ray computed, neurology, neurosurgery

\footnotetext{
${ }^{1}$ Corresponding author, Ehsan Nabovati, Health Information Management Research Center, Kashan University of Medical Sciences, Kashan, Iran; Email: Nabovati@kaums.ac.ir
} 


\section{Introduction}

Mobile technologies as more affordable and accessible information technology in lowincome countries present more opportunities to strengthen health services [1]. In recent years, SMS is one of the most popular strategies for physicians' behavior change via sending feedback and reminders messages [2]. One of the areas in which SMS-based feedback can change physicians' behavior is the CT scan examinations, following the steady CT utilization increase [3]. CT examinations increased from three million in 1980 to 80 million in 2014 [4]. The massive imaging volume imposes a tremendous cost to the health care system, and CT imaging contributes to $1.5-2 \%$ of all cancers [56]. Regardless of these adverse outcomes, it is argued that $20-50 \%$ of imaging procedures may be unnecessary [7]. The literature has reported that sending feedback can significantly improve physicians' behaviors regarding ordering and reduce hospital costs [8]. Therefore, this study was conducted to evaluate the effect of mobile phone SMS-based feedback on residents' head CT scan ordering behavior.

\section{Method}

This quasi-experimentally study was conducted during one-month pre-intervention and two months the intervention phases among the residents of neurology and neurosurgery departments in a general teaching hospital in Iran. To perform the intervention, the CT scans ordered by an individual resident were evaluated every two weeks. Personal SMS-based feedback containing information about CT scans ordered, including the number and cost, the patient exposure to radiation dose, and short educational tips, were provided to the residents. Consequently, the rate of CT per patient in the two phases of the study was analyzed using mean and standard deviation (SD) and chisquare, Fisher's exact test, and paired t-test. Sample content of the SMS feedback is presented in Figure 1.

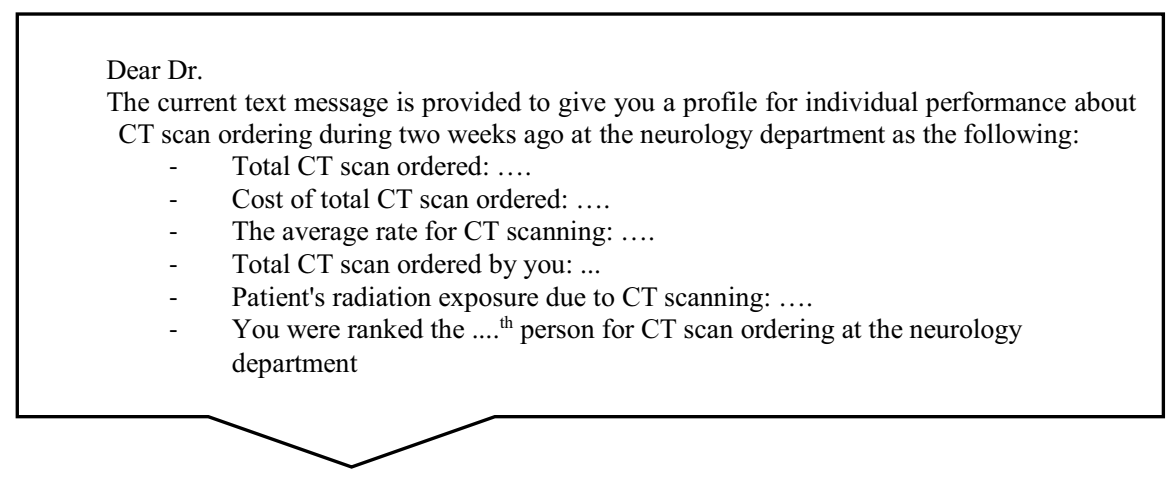

Figure 1. Sample content of the SMS feedback

The current study was supported by Vice-Chancellorship for Research \& Technology at Kashan University of Medical Sciences [Grant number 97204] and National Agency for Strategic Research in Medical Education (NASR) [Grant Number 981867]. 


\section{Results}

The CT scan per patient was 1.98 in the pre-intervention phase and 1.74 postintervention phase. Also, the CT scan ordered per resident in the two phases of the intervention was 11.67 and 11.64, respectively (Table 1).

Table 1. CT scan ordered per patient and per resident during phases of the study

\begin{tabular}{lllll}
\hline Departments & Phases of study & Pre-intervention & Intervention & Total \\
& Variables & & & \\
\hline Neurology & Number of CT & 49 & 178 & 266 \\
& Number of patients & 47 & 132 & 179 \\
& Number of residents & 10 & 10 & 10 \\
& CT scan per patient & 1.68 & 1.41 & 1.48 \\
& CT scan per resident & 7.9 & 9.35 & 8.86 \\
Neurosurgery & Number of CT & 166 & 302 & 468 \\
& Number of patients & 77 & 149 & 226 \\
& Number of residents & 11 & 11 & 2.07 \\
& CT scan per patient & 2.15 & 2.02 & 14.18 \\
& CT scan per resident & 15.09 & 13.72 & 734 \\
& Number of CT & 245 & 489 & 405 \\
& Number of patients & 124 & 281 & 21 \\
& Number of residents & 21 & 21 & 1.81 \\
& CT scan per patient & 1.98 & 1.74 & 11.65 \\
\hline
\end{tabular}

Table 2 indicates the total ordered brain CT scans were 245 for 124 patients in the preintervention phase and 489 for 281 patients in the intervention phase. The mean CT scan ordered per patient decreased from $1.98 \pm 1.09$ in the pre-intervention phase to $1.74 \pm 1.45$ during the intervention phase. However, the decrease of total CT scan ordered was not statistically significant during pre-intervention and intervention phases $(\mathrm{P}=0.106)$.

Table 2. CT scan utilization per patient in two phases of pre-intervention and intervention

\begin{tabular}{llllll}
\hline Departments & Phases of study & $\begin{array}{l}\text { Number of } \\
\text { patients }\end{array}$ & $\begin{array}{l}\text { Number of } \\
\text { CT scans }\end{array}$ & $\begin{array}{l}\text { CT scan per patient } \\
\text { (Mean } \pm \text { SD) }\end{array}$ & $\begin{array}{l}\text { p- } \\
\text { Value }\end{array}$ \\
\hline Neurology & Pre-intervention & 47 & 79 & $1.68 \pm 0.84$ & 0.074 \\
& Post intervention & 132 & 187 & $1.42 \pm 0.87$ & 0.564 \\
Neurosurgery & Pre-intervention & 77 & 166 & $2.16 \pm 1.19$ & 0.106 \\
& Post intervention & 149 & 302 & $2.03 \pm 1.76$ & $1.98 \pm 1.09$ \\
\hline
\end{tabular}

\section{Discussion}

The introduction of SMS-based feedback can reduce head CT scan ordering among residents, whereas this decline was not significant. However, the findings of the current study are in disagreement with Eccles et al. study, in that they reported the reminder messages feedback is ineffective and does not reduce requests for radiological examinations among general practitioners [3]. Sarafi Nejad's study confirms that the feedback via short text messages feedback has a positive impact on prescribing 
parenteral steroids by general practitioners [9]. Since existing literature suggested a lack of consistency in reported results across the studies and the potential for bias, making any direct cause-and-effect relationship between the SMS-based feedback and behavior change by physicians may not be reliable. The limitations of this study include a small sample size and short time period of the study; the post intervention follow up to investigate the long-term effect of SMS intervention on physicians' behavior was cancelled due to the emergence of the COVID-19 pandemic in Iran. Given our poor understanding of the effectiveness of feedback, education [10-12] and SMS interventions on physicians" behavior, it is recommended that further research of higher quality be conducted to investigate the potential benefits of SMS-based feedback on physicians' behavior.

\section{References}

[1] Anstey Watkins JOT, Goudge J, Gómez-Olivé FX, Griffiths F. Mobile phone use among patients and health workers to enhance primary healthcare: A qualitative study in rural South Africa. Soc Sci Med. 2018 Feb;198:139-147. doi: 10.1016/j.socscimed.2018.01.011. Epub 2018 Jan 10. PMID: 29335160

[2] Kurumop SF, Bullen C, Whittaker R, Betuela I, Hetzel MW, Pulford J. Improving health worker adherence to malaria treatment guidelines in Papua New Guinea: feasibility and acceptability of a text message reminder service. PLoS One. 2013 Oct 7;8(10):e76578. doi: 10.1371/journal.pone.0076578. PMID: 24116122; PMCID: PMC3792049

[3] Eccles M, Steen N, Grimshaw J et al. Effect of audit and feedback, and reminder messages on primary-care radiology referrals: a randomised trial. Lancet 2001; 357: 1406-9

[4] Friedman DP, Smith NS. Impact of a Collaborative Radiology Utilization Management Program: Does the Specialty of the Referring Provider Matter? AJR Am J Roentgenol. 2016 Jul;207(1):121-5

[5] Fitzgerald R. Error in Radiology. Clin Radiol. 2001;56(12):938-46

[6] Sarma A, Heilbrun ME, Conner KE, Stevens SM, Woller SC, Elliott CG. Radiation and chest CT scan examinations: what do we know? Chest. 2012 Sep;142(3):750-60

[7] Sheng AY, Castro A, Lewiss RE. Awareness, Utilization, and Education of the ACR Appropriateness Criteria: A Review and Future Directions. J Am Coll Radiol. 2016 Feb;13(2):131-6

[8] Khalifa M, Khalid P. Reducing Unnecessary Laboratory Testing Using Health Informatics Applications: A Case Study on a Tertiary Care Hospital. Procedia Computer Science. 2014;37:253-60

[9] Nejad AS, Noori MR, Haghdoost AA, Bahaadinbeigy K, Abu-Hanna A, Eslami S. The effect of registry-based performance feedback via short text messages and traditional postal letters on prescribing parenteral steroids by general practitioners--A randomized controlled trial. Int J Med Inform. 2016 Mar;87:36-43. doi: 10.1016/j.ijmedinf.2015.12.008. Epub 2015 Dec 19. PMID: 26806710

[10] Meidani Z, Mousavi GA, Kheirkhah D, Benar N, Maleki MR, Sharifi M, Farrokhian A. Going beyond audit and feedback: towards behaviour-based interventions to change physician laboratory test ordering behaviour. J R Coll Physicians Edinb. 2017 Dec; 47(4):339-344. doi: 10.4997/JRCPE.2017.407. PMID: 29537404

[11] Meidani Z, Farzandipour M, Davoodabadi A, Farrokhian A, Kheirkhah D, Sharifi M, Khanghani ME. Effect of reinforced audit and feedback intervention on physician behaviour: a multifaceted strategy for targeting medical record documentation. J R Coll Physicians Edinb. 2017 Sep;47(3):237-242

[12] Davaridolatabadi N, Sadoughi F, Meidani Z, Shahi M. The Effect of Educational Intervention on Medical Diagnosis Recording among Residents. Acta Inform Med. 2013;21(3):173-5 